\title{
Precisamos Diagnosticar o Diabetes Latente Autoimune do Adulto (LADA)?
}

\section{editorial}

MARIA ELIZABETH ROSSI DA SILVA

Serviço de Endocrinologia do Hospital das Clínicas, Faculdade de Medicina da Universidade de São Paulo - USP, São Paulo, SP.
R OSÁrio e COls. (1), em excelente estudo, compararam 54 portadores 1 de LADA com pacientes com diabetes mellitus tipo 2 (DM2). Os pacientes com LADA e títulos elevados de anticorpo anti-GAD tinham idade semelhante àqueles com baixos títulos de anti-GAD, mas menor freqüência dos componentes da síndrome metabólica, representados por menor resistência insulínica e IMC, menor freqüência de hipertensão, menores níveis de triglicérides e maiores de HDL-c. Progrediram para necessidade de insulinoterapia em 84\% decorridos 6 anos versus 50\% daqueles com baixos títulos de anti-GAD e $40 \%$ dos DM2. Pacientes com títulos elevados de anti-GAD insulinizados precocemente mantiveram a reserva insulínica, avaliada pelos níveis de peptídeo C, sugerindo efeito benéfico da insulinização precoce.

Diabetes mellitus é doença heterogênea, com distintos fenótipos, etiologias e determinantes genéticos (2). LADA ainda carece de definição precisa. Situa-se entre DMl e DM2. Há vários questionamentos sobre LADA. É entidade distinta ou um espectro do diabetes imuno-mediado? Requer diagnóstico e terapia específica? Vamos considerar alguns parâmetros:

1) O fenótipo de LADA contempla magros a obesos. Rosário e cols. (1) verificaram no LADA, em relação ao DM2, menor número de componentes da síndrome metabólica, mas estes dados não foram confirmados por outros autores, particularmente quanto à resistência à insulina, que depende do IMC e controle glicêmico. Em estudo onde avaliamos pacientes com diagnóstico de DM2 (3), os portadores de autoanticorpos não diferiram daqueles sem autoanticorpos quanto à idade de diagnóstico, duração do diabetes ou do tratamento antes da introdução da insulinoterapia e prevalência de complicações crônicas. O perfil lipídico era semelhante, exceto por menores níveis de colesterol no grupo com autoanticorpos. Recentemente, Fourlanos e cols. (4) sugeriram cinco critérios clínicos para diferenciar LADA de DM2: idade do início do diabetes $<50$ anos, sintomas agudos ao diagnóstico, IMC $<25 \mathrm{~kg} / \mathrm{m}^{2}$, história pessoal e familiar de doença autoimune. Não incluiu outros componentes da síndrome metabólica como critérios diagnósticos. Assim, a definição de LADA ainda baseia-se na presença de anticorpo anti-GAD em pacientes com início de DM acima de 35 anos de idade e que são independentes de insulina por pelo menos 6 meses após o diagnostico (The Immunology of Diabetes Society).

2) Estudos epidemiológicos sobre LADA esbarram em problemas metodológicos. Idade de início da doença e necessidade precoce de insulina não são parâmetros adequados para definir uma patologia. A idade de aparecimento do DM autoimune no adulto depende do grau de falência das células beta e da sensibilidade à insulina.

3) A dosagem do peptídeo C para avaliar secreção residual de insulina requer cautela. Considerando dois indivíduos portadores de anti$\mathrm{GAD}$, um magro e outro obeso, o magro insulino-sensível, que requer 
menos insulina para manter glicemia normal, terá menos células beta funcionantes ao diagnóstico, o que reduzirá sua resposta a secretagogos ou sensibilizadores de insulina, encurtando o intervalo de tempo para início da insulinoterapia. O obeso, ao desenvolver DM, terá maior reserva de insulina e poderá se beneficiar do uso prolongado de hipoglicemiantes, e será classificado como DM2. A diferença entre eles é a sensibilidade à insulina e não o processo patológico de base. Também não está claro se o nível de peptídeo $\mathrm{C}$ mede acuradamente a massa residual de células beta, pois não há dados de biópsia que estabeleçam relação entre massa de células beta e capacidade secretora de insulina.

4) Marcadores genéticos. Embora diabetes autoimune seja doença poligênica, a maior contribuição vem da região HLA. Em São Paulo, observamos maior freqüência dos alelos de risco HLA$\mathrm{DQB1}{ }^{*} 0201$ e/ou ${ }^{*} 0302$ e $-\mathrm{DRBl}{ }^{*} 03$ e/ou DRB1*04 em mais de $80 \%$ dos DMl e dos alelos classe I do VNTR do gene da insulina em 94\%, enquanto o alelo de proteção $\mathrm{DQB1}{ }^{*} 0602$ foi muito raro nos diabéticos $(2,7 \%)$ (5). Tais alelos de susceptibilidade, também freqüentes no LADA (6), não ajudam na distinção entre LADA e DM2 porque são comuns na população geral (acima de 35\%), ocorrendo freqüentemente no DM2. Também, com a idade, a freqüência de alelos HLA de risco diminui e a de $-\mathrm{DQB1}{ }^{*} 0602$, de proteção, aumenta no LADA. Assim, a genética pouco auxilia na identificação de DM autoimune do adulto.

5) Autoanticorpos, presentes em 11,6\% dos adultos com DM (2), são um diferencial. Os anticorpos mais freqüentes são anti-ilhota-ICA e anti-GAD (2). ICA não é mais dosado por ser método difícil e pouco reprodutível. O diagnóstico de LADA depende do anti-GAD. No entanto, o ponto de corte dos valores positivos de anti-GAD é ainda arbitrário. Rosário e cols. (1) definiram níveis elevados como 17,2 U/mL (correspondente à mediana dos valores do anticorpo) e verificaram que anticorpos em baixos títulos não necessariamente prediziam progressão para insulinoterapia. A presença de autoanticorpo é forte preditor de necessidade precoce de insulina nos mais jovens, mas menos importante nos mais idosos (> 55 anos). Metade dos portadores do anticorpo não irão utilizar insulina em 6 anos (2).

$\mathrm{O}$ anticorpo anti-GAD tem outras limitações. $\mathrm{O}$ LADA que progride para insulinoterapia tem antiGAD contra a porção média e carboxiterminal da molécula, e grande prevalência de autoanticorpos anti- tireóide. Os portadores de anticorpo anti-GAD contra a porção média da molécula têm comportamento semelhante ao DM2, e baixo risco de dependência de insulina. Tal anticorpo poderia resultar de reatividade cruzada com outro antígeno, talvez justificando o fato de anticorpos em baixos títulos muitas vezes desaparecerem. Considerar ainda que anti-GAD não está sempre presente no DM autoimune e a sua ausência não afasta esta patologia.

6) A determinação do anti-GAD auxilia a decidir quando iniciar a insulinoterapia? Os resultados de Rosário e cols. (1) são animadores. O UKPDS (2) também mostrou que os portadores de autoanticorpos progrediam com maior freqüência para insulinoterapia, mas o tratamento com insulina, dieta ou sulfoniluréia não interferiu nesta progressão num seguimento de 10 anos, contrariando tais resultados. Alguns trials em andamento estão avaliando o uso de rosiglitazona, peptídeo HSP e GAD65 em portadores de LADA, mas ainda faltam estudos multicêntricos para referendar este tratamento.

Assim, DM autoimune é altamente prevalente em adultos. Não sabemos se o mecanismo de destruição das células beta é igual ao dos jovens e se irão responder de forma semelhante à terapia imunomoduladora ou imunossupressora. Não há, ainda, recomendação para dosar autoanticorpos em adultos com DM2. Diagnosticar o diabetes autoimune em indivíduos erroneamente classificados como tipo 2 é importante, pois alerta para provável deficiência de insulina, evitando o atraso na insulinoterapia. A freqüente associação entre LADA e autoimunidade tiroidiana também reforça esta avaliação nesses pacientes. Finalmente, a identificação de LADA permite medidas preventivas em centros especializados, como a aqui apresentada, para proteger a função residual das células beta.

\section{REFERÊNCIAS}

1. Rosário PWS, Reis JS, Fagundes TA, Calsolari MR, Amim R, Silva SC, et al. Latent Autoimmune Diabetes in Adults (LADA): usefulness of anti-GAD antibody titers and benefit of early insulinization. Arq Bras Endocrinol Metab 2007; 51(1):52-58.

2. Davis TM, Wright AD, Mehta ZM, Cull CA, Stratton IM, Bottazzo GF, et al. Islet autoantibodies in clinically diagnosed type 2 diabetes: prevalence and relationship with metabolic control (UKPDS 70). Diabetologia 2005; 48(4):695-702.

3. Silva MER, Ursich MJM, Rocha DM, Fukui RT, Correia MRS, Marui S, et al. Diabetes autoimune em adultos: características clínicas e autoanticorpos. Arq Bras Endocrinol Metab 2003; 47(3):248-55.

4. Fourlanos S, Perry C, Stein MS, Stankovich J, Harrison LC, Colman PG. A clinical screening tool identifies autoimmune diabetes in adults. Diabetes Care 2006; 29(5):970-5. 
Silva

5. Davini E, Silva MER, Alves LI, Latronico AC, Correia MRS, Fukui RT, et al. Locus INS VNTR conferred independent risk to type 1 diabetes mellitus in Brazilians. The Endocrine Society's 81th Annual Meeting, 2006, Boston. Program \& Abstracts. 2006. P3-490, p. 760.

6. Desai M, Zeggini E, Horton VA, Owen KR, Hattersley AT, Levy $\mathrm{JC}$, et al. An association analysis of the HLA gene region in latent autoimmune diabetes in adults. Diabetologia 2007; 50(1):68-73
Endereço para correspondência:

Maria Elizabeth Rossi da Silva

Laboratório de Investigação Médica LIM-18

Av. Dr. Arnaldo 455, sala 3324

01246-903 São Paulo, SP

E-mail: mbeth@usp.br 